\title{
Flow resistance of coaxial breathing systems: investigation of a circuit disconnect
}

A clinical incident involving an undetected disconnection occurred during the use of a CPRAM coaxial breathing circuit. The flow resistance of this circuit was evaluated and compared with that of a Bain circuit to determine the factors involved. $A$ differential pressure transducer was used to monitor the pressure drop across each circuit during simulation of controlled ventilation with a fresh gas flow of $6 \mathrm{~L} \cdot \mathrm{min}^{-1}$. An Ohio V5 anaesthesia ventilator was adjusted to different flow rates and tidal volumes and a test lung simulated an airway resistance of $2.7 \mathrm{~cm}$ $\mathrm{H}_{2} \mathrm{O} \cdot \mathrm{L}^{-1} \cdot \mathrm{sec}$ and a compliance of $0.05 \mathrm{~L} \cdot \mathrm{cm} \mathrm{H}_{2} \mathrm{O}^{-1}$. Absolute pressure at the ventilator was also monitored when the circuit was disconnected from the test lung. The CPRAM circuit displayed a pressure drop from the ventilator to the endotracheal tube of $6.3 \mathrm{~cm} \mathrm{H} \mathrm{H}_{2} \mathrm{O}$ at $60 \mathrm{~L} \cdot \mathrm{min}^{-1}$, about twice that found with the Bain. A disconnection at the tracheal connector produced an absolute pressure at the ventilator of $9.6 \mathrm{~cm} \mathrm{H}_{2} \mathrm{O}$ with the $C P R A M \circlearrowleft$ and $5.5 \mathrm{~cm} \mathrm{H}_{2} \mathrm{O}$ with the Bain. Since the ventilator low pressure alarm was preset to $9.2 \mathrm{~cm} \mathrm{H}_{2} \mathrm{O}$, the alarm provided a warning with the Bain but not the CPRAM The elevated flow resistance of the CPRAM circuit was attributed 10 a restriction in the flow area at the patient end of the circuit. Capnographs or adjustable low-pressure alarms provide more reliable monitoring for breathing circuit disconnects.

Un incident clinique impliquant une déconnextion non détectée est survenue durant l'utilisation d'un circuit coaxial respiratoire CPRAM La résistance au flot de ce circuit a été évaluée et comparée avec celle du circuit Bain afin de déterminer les

\section{Key words}

EQUIPMENT: alarms, circuits, coaxial, Bain, CPRAM.

From the Research and Development Section, Bureau of Radiation and Medical Devices, Health Protection Branch, Health and Welfare Canada.

Address correspondence to: Dr. A. Sinclair, Bureau of Radiation and Medical Devices, Health Protection Branch Building, Tunney's Pasture, Ottawa, Ontario, Canada K1A 0L2.

Accepted for publication Sth September, 1991.
Alex Sinclair PhD, Jos Van Bergen facteurs impliqués. Un transducteur de pression différentielle a été utilisé afin de surveiller la chute de pression à travers chacun des circuits durant la simulation d'une ventilation contrôlée avec un débit de gaz frais de $6 \mathrm{~L} \cdot \mathrm{min}^{-1}$. Un ventilateur d'anesthésie Ohio V5 a été ajusté pour des débits et des volumes courants variables et un poumon artificiel a simulé des résistances des voies aériennes de $2,7 \mathrm{~cm} \mathrm{H}_{2} \mathrm{O} \cdot \mathrm{L}^{-1}$ sec et une compliance de $0,05 \mathrm{~L} \cdot \mathrm{cm} \mathrm{H} \mathrm{H}_{2} \mathrm{O}^{-1}$. La pression absolue du ventilateur a aussi été mesurée quand le circuit fut déconnecté du poumon artificiel. Le circuit CPRAM a démontré une chute de la pression du ventilateur au tube endotrachéal de $6,3 \mathrm{~cm} \mathrm{H}_{2} \mathrm{O}$ à $60 \mathrm{~L} \cdot \mathrm{min}^{-1}$. le double de la valeur constatée avec le circuit de Bain. Une déconnection au niveau du connecteur trachéal a produit une pression absolue du ventilateur de $9,6 \mathrm{~cm} \mathrm{H}_{2} \mathrm{O}$ avec le CPRAM et de $5,5 \mathrm{~cm} \mathrm{H}_{2} \mathrm{O}$ avec le circuit de Bain. Etant donné que l'alarme de basse pression du ventilateur était réglé à 9,2 $\mathrm{cm} \mathrm{H}_{2} \mathrm{O}$, l'alarme a fonctionné dans le circuit Bain et non avec le CPRAM La résistance au débit élevé du CPRAM fut attribuée à la diminution de la surface au niveau de la connection du circuit au patient. Des capnographes ou des alarmes de basse pression ajustable fourniraient un moyen de surveillance plus sécuritaire pour détecter une déconnection du circuit.

The popularity of the Bain breathing circuit, introduced to anaesthesia almost two decades ago, ${ }^{1}$ has encouraged the development of competing designs. One of these, the CPRAM* Breathing Circuit by Gibeck-Dryden Corporation, Indianapolis, introduced a modification that extends the fresh gas outlet to near the end of the connector (patient end). This fitting was tapered and side vents were included to achieve "vortex mixing," design features that were promoted by the manufacturer as improving the mixing of the exhaled gases and providing lower resistance to expiratory flow.

Because of this projection of the inner tube into the patient connector, interference with exhalation can occur if a thick walled connector (e.g., low dead space component) is used. ${ }^{2}$ The manufacturer included an insert in their packaging that warned against the use of low dead

*Trademark 


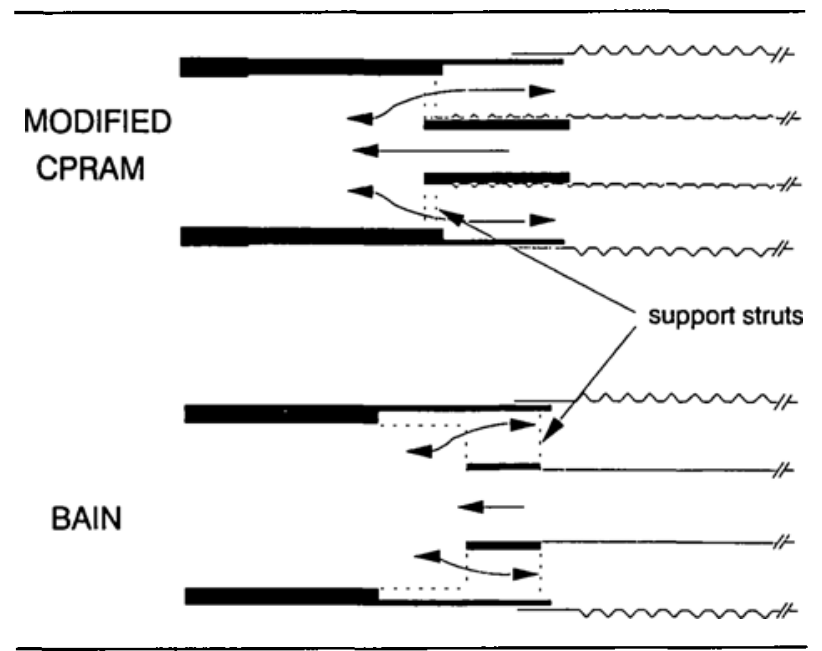

FIGURE I Geometrical profiles of the CPRAM $\$$ and Bain coaxial breathing circuits at the patient end of the circuit.

space connectors. Furthermore, the manufacturer developed a modified version of this circuit in which the inner tube extension (i.e., the "vortex mixing" feature) was removed, moving the fresh gas exit point back towards that found in the Bain breathing circuit. Figure 1 illustrates the geometry associated with this modified circuit.

In spite of the manufacturer's warnings with the unmodified circuit, Canadian anaesthetists remained concerned with this product, particularly since there was no readily identifiable marking to distinguish between the modified and unmodified versions of this circuit (other than simple visual inspection of the patient connector). As a consequence, the Canadian distributor of the CPRAM, in consultation with the Health Protection Branch, agreed to withdraw the unmodified circuit from sale.

The following incident, reported to the Health Protection Branch, raised further questions about the safety of the modified version of the CPRAM circuit. During a clinical procedure in which this modified CPRAM circuit was used with an Ohio V5 Ventilator, a disconnect occurred at the endotracheal tube without activating the low-pressure alarm on the ventilator. The anaesthetist was alerted to the existence of a problem by the low readings from a pulse oximeter, and took corrective steps before any complications occurred. Subsequent simulation with a Bain circuit revealed the ventilator alarm to be functioning normally.

Since the latter observations suggested that the flow resistance of the CPRAM breathing circuit was higher than that of the Bain, the flow characteristics of these two circuits were studied.

\section{Method}

Two coaxial circuits were evaluated to determine their respective flow resistance: a modified CPRAM Breathing
TABLE I Pressure drop from the ventilator outlet port to the patient end of a coaxial breathing circuit during controlled ventilation at 60 $\mathrm{L} \cdot \mathrm{min}^{-1}$ inspiratory flow (with and without a $90^{\circ} \mathrm{elbow}$ adaptor attached)

\begin{tabular}{lll}
\hline & \multicolumn{2}{l}{ Pressure drop $\left(\mathrm{Cm} \mathrm{H}_{2} \mathrm{O}\right)$} \\
\cline { 2 - 3 } Circuit & No elbow & Elbow \\
\hline Bain & 3.1 & 4.2 \\
CPRAM & 6.3 & 7.3 \\
\hline
\end{tabular}

Circuit (specialty circuit component suffix -97 ) by Dryden Corporation of Indianapolis, Indiana; and a Kendall Curity Bain Breathing Circuit by The Kendall Company, Boston, Massachusetts.

Simulation of the reported incident was conducted at the hospital involved with an Ohio Modulus anaesthesia machine adjusted to provide a fresh gas flow of $6 \mathrm{~L} \cdot \mathrm{min}^{-1}$ oxygen. An Ohio V5 anaesthesia ventilator provided controlled ventilation (same settings as used clinically) and the patient was simulated with a Bio-Tek Model VT-1 adult ventilator tester (i.e., test lung). The test lung was adjusted to an airway resistance of $2.7 \mathrm{~cm} \mathrm{H}_{2} \mathrm{O} \cdot \mathrm{L}^{-1} \cdot \mathrm{sec}$ and a compliance of $0.05 \mathrm{~L} \cdot \mathrm{cm} \mathrm{H}_{2} \mathrm{O}^{-1}$.

Circuit pressures (differential and gauge) were measured with a Validyne Model DP7 pressure transducer and Model CD23 digital transducer indicator, and recorded on a Nicolet NIC-310 digital oscilloscope. The pressure sensing lines were positioned at the pressure monitoring port on the ventilator and at the airway pressure monitoring port (i.e., inlet) of the test lung. Differential pressure measurements were obtained by monitoring the pressure difference between these two sites. Gauge (i.e., absolute) pressure measurements at the ventilator site were also recorded during simulations of a disconnect. Finally, measurements were made with and without the $90^{\circ}$ endotracheal tube connector (elbow) in place to illustrate the flow resistance associated with this component.

The above tests were repeated in a laboratory setting with an Ohio anaesthesia ventilator adjusted to different inspiratory flow rates and tidal volumes. A pressuresensing T-piece was also inserted at the machine end of the coaxial circuit to enable measurement of the pressure drop from the bag mount to the endotracheal tube connector. The inspiratory flow rate delivered by the ventilator was monitored by recording the analogue output (flow) of the test lung. The peak differential pressures were related to the corresponding peak flow rates.

\section{Results}

The pressure drop (i.e., differential pressure) across each circuit during simulated ventilation with the test lung at the hospital is summarized in Table $I$. The results with the elbow removed show that the CPRAM circuit has twice 
TABLE II Gauge pressures at ventilator outlet port during a disconnect at the endotracheal tube (with and without an elbow)

\begin{tabular}{lll}
\hline & \multicolumn{2}{l}{ Gauge pressure $\left(\mathrm{cm}_{2} \mathrm{O}\right)$} \\
\cline { 2 - 3 } Circuit & No elbow & Elbow \\
\hline Bain & 4.0 & 5.5 \\
CPRAM & 8.2 & 9.6 \\
\hline
\end{tabular}

the flow resistance of the Bain circuit. Differences with and without the 90 degree elbow attached indicated the considerable pressure drops (e.g., $1 \mathrm{~cm} \mathrm{H}_{2} \mathrm{O}$ ) associated with these components alone.

Table II shows the maximum pressures (gauge) that were measured at the ventilator sampling port when complete disconnects were simulated. These are the pressures that are sensed by the low pressure alarm during a disconnect. The ventilator low pressure alarm was activated for all of the above disconnect simulations except when the CPRAM was used with an elbow. Although the preset threshold alarm point is intended to be $10 \mathrm{~cm} \mathrm{H}_{2} \mathrm{O}$, the actual alarm activation point was measured to be 9.2 $\mathrm{cm} \mathrm{H}_{2} \mathrm{O}$.

These gauge pressures are higher than the differential pressures recorded in Table I largely because of the additional pressure drop at the leakage site and the higher flow rates associated with a disconnect.

Figure 2 illustrates the change in pressure drop for both circuits as the inspiratory flow control on the ventilator was adjusted from its minimum value $\left(30 \mathrm{~L} \cdot \mathrm{min}^{-1}\right)$ to its maximum $\left(90 \mathrm{~L} \cdot \mathrm{min}^{-1}\right)$. Changing the tidal volume setting had no effect on differential pressures.

\section{Discussion}

The results show that the CPRAM circuit introduced a considerable increase in the resistance to flow compared with that found using the Bain circuit. Furthermore, this elevation in flow resistance is sufficient to mask complete disconnects at the endotracheal tube when controlled ventilation is provided with an Ohio V5 anaesthesia ventilator, or its equivalent.

The alarm failure is related to two characteristics of the ventilator. Firstly, the Ohio V5 ventilator is of a descending bellows (during expiration) type, allowing room air to be drawn into the bellows (from the point of disconnection) during expiration, and enabling inspiratory flows to be maintained. The disadvantages with this type of ventilator have previously been reported. ${ }^{3}$ Although standards ${ }^{4}$ now discourage this type of ventilator, they are still in common use.

Secondly, the low-pressure alarm on the ventilator utilizes a preset, low-pressure activation point $(10 \mathrm{~cm}$
CIRCUIT PRESSURE DROP VS VENTILATOR FLOW RATE

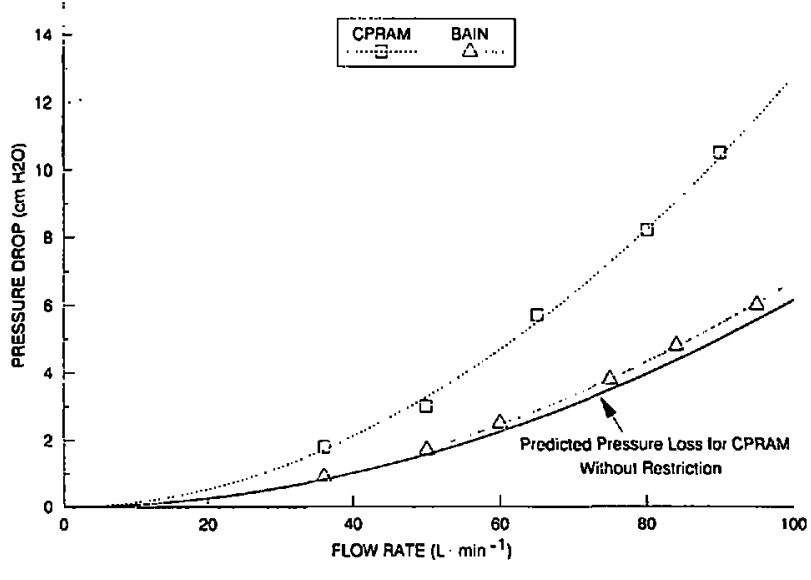

FIGURE 2 Flow resistance of the CPRAM ${ }^{\oplus}$ and Bain coaxial circuits. Peak pressure drop from the bag mount to the tracheal tube connection is plotted against the peak inspiratory flow delivered by an Ohio anaesthesia ventilator. The coaxial circuit was connected to a test lung. Also shown for comparison is the predicted pressure drop of the CPRAM circuit with the restriction removed.

$\mathrm{H}_{2} \mathrm{O}$ ). An adjustable low-pressure alarm that could be set to activate just below the required patient ventilation pressures would have provided an immediate warning in this case. Pryn and Crosse ${ }^{5}$ reported similar concerns with disconnect alarms and recommended that the alarm limits be set only marginally below the peak inspiratory pressure.

The role of the pulse oximeter in this incident, by alerting the anaesthetist to a problem, raises another important point. The pulse oximeter responds to the physiological consequences of the disconnect and is therefore a late indicator of this device failure. As noted by Verhoeff and Sykes, ${ }^{6}$ delays of several minutes can occur before an alarm set at $90 \%$ saturation warns of a hypoxic event. More importantly, the rapid desaturation that occurs below this alarm level means that very little time is available to prevent hypoxic damage. Furthermore, the authors noted that vasoconstriction and venous congestion can further delay the alarm activation. By way of contrast, a capnograph would have provided an immediate warning of this disconnect and, by virtue of the information provided, focused attention directly to the problem.

There are differences in the physical dimensions of the two circuits (e.g., the CPRAM is $20 \%$ longer and the area between inner and outer coaxial tubes is about $20 \%$ smaller) which would be expected to contribute to higher pressure losses with the CPRAM. However, these would not account for the pressure losses observed, suggesting that other factors in the CPRAM design are responsible.

As shown in Figure 1, the two circuit designs differ at the patient end of the circuit. The support struts on the 
ESTIMATED AREA PROFILE AT PATIENT END OF COAXIAL CIKCUITS

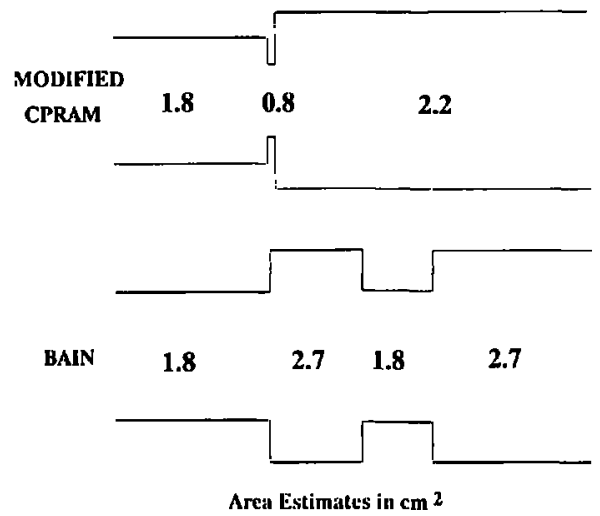

FIGURE 3 Simplified view of the area profiles for the CPRAM and Bain coaxial circuits at the patient end of the circuit. This area profile corresponds to the longitudinal view illustrated in Figure 1.

CPRAM are at right angles to the connector axis. As a consequence, the minimum flow area is defined by the difference between the area of the $15 \mathrm{~mm}$ (ID) connector and that of the $10 \mathrm{~mm}$ (OD) fresh gas line (less the area taken up by the support struts). This area is about $0.8 \mathrm{~cm}^{2}$ or less than half the flow area between the inner and outer coaxial tube.

By orienting the struts along the lateral axis of the connector, the Bain circuit positions the fresh gas end beyond the $15 \mathrm{~mm}$ ID connector. The larger diameter at this point results in a minimum cross-sectional area to flow that is about $1.8 \mathrm{~cm}^{2}$, more than twice that of the CPRAM.

The reduction in flow area at the fresh gas exit point is equivalent to introducing an orifice in the flow channel. This concept is illustrated in Figure 3, where the circuit has been simplified to correspond to an equivalent pipe system with an orifice. Although the internal diameter of the $22 \mathrm{~mm}$ outer tubing is about $20 \mathrm{~mm}$, the cross-sectional area of the fresh gas line reduces the effective flow area to that indicated. The differences between these two designs are evident in this illustration, with the CPRAM orifice representing a much smaller fraction of the primary flow area.

The pressure drop for oxygen flow through an orifice (7) can be expressed as

$\mathrm{P}=0.66\left(\mathrm{Q} / \mathrm{A}^{*}\right)^{2}$

where $P$ represents the pressure drop $\left(\mathrm{cm} \mathrm{H}_{2} \mathrm{O}\right), \mathrm{Q}$ is the flow rate $\left(\mathrm{L} \cdot \sec ^{-1}\right)$ and $\mathrm{A}^{*}$ is the effective flow area through the orifice $\left(\mathrm{cm}^{2}\right)$. The effective flow area of the orifice depends on its geometry. For a sharp-edged orifice like that associated with the CPRAM (Figure 3), the effective flow area is about $65 \%$ of the actual orifice area.
Consequently, for a flow rate of $1 \mathrm{~L} \cdot \mathrm{sec}^{-1}$ and an actual orifice area of $0.8 \mathrm{~cm}^{2}$, we predict a pressure drop of 2.4 $\mathrm{cm} \mathrm{H}_{2} \mathrm{O}$. For a blunt-edged orifice like that associated with the Bain, the orifice coefficient is about I, and the corresponding pressure drop would be about $0.2 \mathrm{~cm} \mathrm{H}_{2} \mathrm{O}$.

Equation 1 shows that the pressure drop across the orifice is proportional to the square of the flow rate. Thus an increase in the ventilator inspiratory flow from 60 $\mathrm{L} \cdot \min ^{-1}$ to $90 \mathrm{~L} \cdot \min ^{-1}$ would more than double the pressure losses (e.g., $5.5 \mathrm{~cm} \mathrm{H}_{2} \mathrm{O}$ for the CPRAM and 0.5 $\mathrm{cm} \mathrm{H}_{2} \mathrm{O}$ for the Bain) associated with the restrictions. We would therefore predict a difference between the Bain and CPRAM of $2.2 \mathrm{~cm} \mathrm{H}_{2} \mathrm{O}$ at $60 \mathrm{~L} \cdot \mathrm{min}^{-1}$, widening to 5.0 $\mathrm{cm} \mathrm{H}_{2} \mathrm{O}$ at $90 \mathrm{~L} \cdot \min ^{-1}$. These theoretical predictions are consistent with the measurements illustrated in Figure 2 and that reported in the tables. In Figure 2, the anticipated pressure drop of the CPRAM with the restriction removed is shown for comparison. This was obtained by subtracting the theoretical calculations of orifice pressure drop at various flow rates from the measured values with the CPRAM.

The above tests and theoretical calculations were based on $100 \%$ oxygen as the carrier gas. Nitrous oxide has a density about $40 \%$ higher than that of oxygen, so that a $30 / 70$ (oxygen/nitrous) anaesthetic mixture would have a density more than $25 \%$ higher than the test gas. Since the constant in equation I is proportional to gas density, the corresponding pressure losses during an anaesthetic procedure would be about $25 \%$ higher than those indicated.

If adequate warning of a disconnect is not an issue, is the higher flow resistance of the CPRAM still important? Dennison et al. ${ }^{8}$ reported an elevated flow resistance with several breathing system configurations. The addition of humidifiers (Bennett Cascade and Engstrom Edith) and bacterial filters to the breathing circuits elevated the flow resistance by about 6 to $7 \mathrm{~cm} \mathrm{H} \mathrm{H}_{2} \mathrm{O} \cdot \mathrm{L}^{-1} \cdot \mathrm{s}$ (at a flow of 1 $\mathrm{L} \cdot \mathrm{s}^{-1}$ ) over that attributable to the tracheal tube by itself, values that are only slightly higher than that found with the CPRAM. The authors expressed concerns about the implication of this elevated flow resistance towards the increased work of breathing and the difficulties associated with weaning.

\section{Conclusion}

The modified CPRAM breathing circuit exhibits a higher flow resistance than the Bain breathing circuit. This increase in flow resistance appears to be related to the design at the fresh gas exit point, where the restriction in flow area is greater than that found with the Bain circuit. Because of this flow resistance, the preset low pressure alarm may fail to warn of an endotracheal tube disconnect 
when using the CPRAM with an Ohio V5 Anaesthesia Ventilator.

\section{References}

1 Bain JA, Spoerel WE. A streamlined anaesthetic system. Can Anaesth Soc J 1972; 19: 426-35.

2 ECRI. Breathing Circuits, Anesthesia. Health Devices Alerts Sept 8, 1989: 2-3.

3 Health Protection Branch. Medical Devices Alert No. 40: Coaxial Breathing Circuits. October 1, 1981.

4 Canadian Standards Association. Z168.5.1-M87 Anaesthesia Ventilators. Rexdale: 1987.

5 Pryn SJ, Crosse MM. Ventilator disconnexion alarm failures. The role of ventilator and breathing system accessories. Anaesthesia 1989; 44: 978-81.

6 Verhoeff $F$, Sykes $M K$. Delayed detection of hypoxic events by pulse oximeters: computer simulations. Anaesthesia 1990; 45: 103-9.

7 Ower E, Pankhurst RC. The Measurement of Air Flow. 5th ed. New York: Pergamon Press, 1977.

8 Dennison FH, Taft AA, Mishoe SC, Hooker LL, Eatherly $S B$, Beckham RW. Analysis of resistance to gas flow in nine adult ventilator circuits. Chest 1989; 96: 1374-9. 